Cuad. invest. hist. Brocar n. 16 (1990). Págs. 7-18.

\title{
EL RECINTO MEDIEVAL DE MONTE CANTABRIA (LOGROÑO, LA RIOJA)
}

\author{
Carlos Pérez Arrondo \\ Javier Ceniceros Herreros \\ Juan Manuel Tudanca Casero
}

\begin{abstract}
RESUMEN.- La campaña de 1990 supone la continuación de los trabajos arqueológicos realizados años atrás en el cerro de Monte Cantabria, en este caso aplicados al lado E. del sistema defensivo. Los datos obtenidos concretan las caracteristicas de la ocupación celtibérica y medieval del recinto.

SUMMARY.- 1990 Campaign suposes the continuation of the archaeological works developed some years ago in the area of Monte Cantabria. In this case, the works have been centrered on the Eastern side of the defensive system. The data obteined define the characteristics of the celtiberian and medieval occupation of the area with a highes precision.
\end{abstract}

Palabras clave: Arqueología del Valle del Ebro, celtíberos, arqueología medieval, poliorcética, necrópolis medieval.

\section{INTRODUCCION: LAS EXCAVACIONES ANTERIORES A 1990. ESTADO DE LA CUESTION}

Situado junto a la ciudad de Logroño, en la margen izquierda del Ebro y a algo más de $100 \mathrm{~m}$. sobre el actual cauce del río, el yacimiento de Monte Cantabria ha sido excavado en dos fases. La primera en los años 1940 y 1945, con trabajos en la zona de acceso, al norte del recinto fortificado, e intramuros de los lienzos norte y este; la segunda a partir de 1977 en varias campañas que se extendieron a los primeros años de la década de los 80 .

El proyecto del Excmo. Ayuntamiento de Logroño de urbanizar la zona del cerro sobre la ciudad devuelve protagonismo a un yacimiento arqueológico que al menos desde el siglo III antes de Cristo y con una decisiva importancia en los siglos XII-XIII, se configura como un notable precedente de ocupación humana de esta zona de confluencia entre el Iregua y el Ebro, en que hoy se asienta la capital de La Rioja. 
La zona excavada ocupa una antigua terraza destacada por sobreexcavación sucesiva del lecho fluvial, presentando una base de cantos rodados pequeños cimentados en una matriz calizo-arenosa. El conjunto descansa sobre terrenos miocenos, propios de la depresión del río y presenta una topografía llana, delimitada en su parte sur por escarpes sobre el Ebro que han llegado a eliminar por completo la fortificación, si es que existió en esta zona.

Los trabajos llevados a cabo en el área fortificada del cerro se iniciaron con prospecciones previas desde 1940 y una excavación extensa en 1945, bajo la dirección de A. Fernández de Avilés y B. Taracena. Desgraciadamente estas labores no aportaron publicaciones definitivas y el descarne parcial del recinto murado supuso una aceleración de la incidencia erosiva ${ }^{1}$. Ya en nuestros días, iniciamos un trabajo sistemático en la zona oeste del recinto, zona más preservada dada la dirección de los vientos y la protección del muro circundante, no descarnado en la campaña de la primera mitad del siglo.

Para el estudio de los tramos propuestos, que hoy forman una extensa zona de 1.029 m., se plantearon 4 cortes estratigráficos independientes, se siguió el sistema de coordenadas cartesianas y avance por tallas artificiales de $10 \mathrm{~cm}$., durante la primera campaña. Después trabajamos por suelos arqueológicos, según la estratigrafía previa obtenida.

Nuestro estudio fue subvencionado por el Ministerio de Cultura, el Instituto de Estudios Riojanos y la Diputación Provincial, en las primeras campañas, y por la Comunidad Autónoma de La Rioja y el Ayuntamiento de Logroño en las dos últimas. A estas instituciones y a todos los que de uno u otro modo han colaborado en dar a la luz estas lineas nuestro agradecimiento desde aqui ${ }^{2}$.

Por último digamos que la primera campaña y sus observaciones estratigráficas preliminares se publicaron ya en 1979 , que los hallazgos numismáticos merecieron un artículo detallado en el V Congreso Nacional de Nimismática, reunido en Sevilla y que conclusiones parciales en torno al recinto medieval formaron parte de una aportación al I Congreso de Arqueología Medieval celebrado en $1985^{3}$.

El yacimiento de Monte Cantabria presenta, en el estado actual de las investigaciones, las siguientes fases de ocupación:

Una fase prehistórica, con dos niveles celtibéricos. El nivel inferior representa momentos tempranos de indigenismo, con habitaciones de planta cuadrangular,

1 TARACENA, Blas (1941): "La Antigua población de La Rioja". Archivo Español de Arqueologla. TARACENA, B. (1942): "Restos romanos en La Rioja". Archivo Español de Arqueología. GARCIA PARDO, J. (1949): La ciudad de Logroño. Logroño. FERNANDEZ DE AVILES, A. (1956): "Excavaciones en Logroño (1945). Monte Cantabria y El Redal". Berceo.

2 Citaremos especialmente a los doctores Sebastián Andrés Valero, medievalista y atqueólogo y Fernán Alonso, director del Laboratorio de Geocronología del C.S.I.C. en Madrid. Asi mismo, contamos en la coordinación de los trabajos de campo con nuestros compañeros y amigos, los licenciados Dĩa. Susana López de Castro y D. José Antonio Tirado Martínez.

3 PEREZ ARRONDO, C. L. (1979): "Excavaciones arqueológicas en Monte Cantabria. 1977. Informe preliminar". Cuadernos de Investigación. Geografía e Historia. PEREZ ARRONDO, C. L. (1983): "Monedas medievales en el yacimiento de Monte Cantabria". V Congreso Nacional de Numismática. Sevilla. PEREZ ARRONDO, C. L. ANDRES VALERO, S. (1986): "El poblamiento medieval de Monte Cantabria (Logroño, La Rioja). I Congreso nacional de Arqueologia Medieval. Tomo, IV. Huesca, 1985. Zaragoza. 
hogares circulares de arcilla y cerámicas a mano y a torno. Esta fase primitiva está datada alrededor del 290 a.C. por C14 (C.S.I.C. 628) ${ }^{4}$.

El nivel superior, dentro de la fase celtibérica, presenta restos del muro de circunvalación del recinto, con abundantes cerámicas pintadas, $\mathrm{y}$ algunas inhumaciones infantiles, bajo el pavimento de las habitaciones. Los restos cerámicos nos ofrecen una datación relativa entre los siglos II-I a.C. y el siglo I d.C.

Sobre la fase prehistórica se extiende, arrasándola en gran medida, una fase de ocupación medieval con amurallamiento en lienzo simple, lineal-quebrado sin cubos y una extensa zona amurallada, protegida por bastiones semicirculares, en las zonas este y norte del conjunto excavado. Hallazgos cerámicos y numismáticos determinan esta ocupación en pleno siglo XII y XIII. Destaquemos 4 monedas de plata de Alfonso I (1104-1134) en perfecto estado de conservación y coincidentes con los textos que sitúan al rey en esta zona del valle del Ebro, precisamentre entre Marzo y Mayo de $1132^{5}$.

En una fase final, el conjunto sirvió de necrópolis, aprovechándose los lienzos y bastiones para cobijar algunas tumbas de lajas, otras fosas simples de inhumación excavadas en la grava e incluso restos sueltos, todo ello extramuros del conjunto amurallado y, en varios casos, alterando su estructura original.

\section{LAS EXCAVACIONES ARQUEOLOGICAS DE 1990 Y SU INCIDENCIA EN EL ANALISIS DE LAS FORTIFICACIONES MEDIEVALES}

\section{A) LOS TRABAJOS ARQUEOLÓGICOS EN EL CERRO}

La campaña de 1990, pretendió por un lado corroborar y completar los datos hasta aquí expuestos y por otro preparar el yacimiento de Monte Cantabria de cara a su integración en el plan municipal de urbanización del cerro, logrando de la mejor forma posible la preservación de los restos arqueológicos y su posible exposición "in situ". Todo ello con el acuerdo conjunto de la Comunidad Autónoma y el Ayuntamiento, respecto a la financiación de los trabajos arqueológicos.

La investigación ha pretendido básicamente salvar, no sólo unos datos científicos, sino especialmente una realidad histórica, que se encuentra enraizada en los orígenes de nuestra ciudad, y podrá, gracias a la actuación conjunta de Ayuntamiento de Logroño

4 El laboratorio de Geocronología del C.S.I.C. ha datado, sobre muestra de madera carbonizada, cuadro 115 AC, el nivel celtibérico, en muestra CSIC-628, dando la fecha 2240-50. (290 b. c.). Corresponde al nivel más antiguo de ocupación del cerro en esta zona.

5 THOMSEN, R. (1956): "Ensayo de sistematización de las monedas navarras y aragonesas de los siglos XI y XII". Numisma, año VI, n. 20. VILlACAMPA, M. A. (1979): "Historiografía de Monte Cantabria (Logroño)". Cuadernos de Investigación Histórica. Geografia e Historia. Logroño, tomo V, fasc. 1. UBIETO, A. (1960): Cartulario de Albelda. Textos Medievales 1. Valencia: (documentos 28-33). MARTIN DUQUE, A. (1983): Documentación Medieval de Leire (siglos IX al XII). Pamplona (documentos 23-30-31). LACARRA, J. M. (1947-48): "Documentos para el estudio de la reconquista y repoblación del valle del Ebro". Estudios de la Edad Media de la Corona de Aragón, III. Zaragoza (documentos 167). LACARRA, J. M. (1950): "Documentos para el estudio de la reconquista y repoblación del valle medio del Ebro". Estudios de la Edad media de la Corona de Aragón, V. Zaragoza (documento 330). 
y Comunidad Autónoma de La Rioja, ser ofrecida al ciudadano, como lección viva del pasado, junto a una intervención urbanística que recupere una zona importante de nuestro entorno geográfico.

La actuación concreta de los dos meses largos de campaña en Septiembre/Octubre/ Noviembre de 1990 se resumen en:

-Excavación de un conjunto de lienzos en la muralla medieval (zonas este/norte) con más de $140 \mathrm{~m}$. de longitud.

-Excavación de cinco baluartes o bastiones semicirculares de reforzamiento en la poliorcética de la muralla.

- Rescate de varias tumbas adosadas al muro este (necrópolis de reutilización del amurallamiento). Asímismo restos humanos sueltos (sin estructura de fosas o tumbales).

-Limpieza y consolidación del barrio medieval del sector oeste, y reconstitución de su urbanística.

-Prospección general del cerro y análisis de futuras intervenciones según plan previsto ${ }^{6}$.

\section{B) ANÁLISIS DEL SISTEMA DEFENSIVO}

\section{Aspecto general de las fortificaciones (fig. 1)}

La zona fortificada sobre la meseta de Monte Cantabria ocupa unos 16.000 metros cuadrados, frente a las casi 11 hectáreas del total. Hemos de advertir que los cultivos de viñas y una extensisima gravera han erosionado y degradado totalmente la superficie no fortificada, poniendo incluso en peligro la parte norte y este de la zona amurallada. Por otro lado, anotemos que en casi toda la extensión de la cumbre aparecían ingentes cantidades de cerámica celtibérica, en zonas ya completamente degradadas, que nos hacen pensar en un potentísimo hábitat indígena.

Los restos medievales sólo se localizan en el citado extremo sudoeste, dentro del recinto amurallado. La planta del recinto, cuadrangular irregular, muestra dos etapas mínimas de construcción, la primera con los muros de la zona oeste, en línea quebrada y sin cubos (el cubo de la zona excavada fue claramente adosado al lienzo con posterioridad), casi hasta la zona de entrada norte.

La zona de acceso, todo el lienzo norte y el muro este correspodnen a la segunda etapa constructiva, con cubos estructuralmente trabados con el lienzo de la muralla.

La zona oeste, siglos XI-XII, se presenta en parte construida con sillarejo asentado a hueso, y con canto rodado como base, dentro de la matriz caliza de la terraza del río, habiéndose arrasado los niveles celtibéricos intramuros del recinto. Esta zona antigua presenta refacciones de argamasas con cerámica aplastada, un mortero bastante deleznable, idéntico al empleado en la conclusión del recinto, ya en el siglo XII.

Creemos que el perímetro del siglo XI se amplió con un trazado más lineal ya en el siglo XII. Esta segunda zona, protegida en tramos por cubos semicirculares de $4 \mathrm{~m}$. de

6 Los planes del Excmo. Ayuntamiento de Logroño y la Comunidad Autónoma de La Rioja tienen previsto una última campaña intensiva en 1991. Durante estos trabajos se pretende liberar el conjunto amurallado en sus zonas norte y oeste y excavar parte del barrio medieval intramuros, así como comprobar los niveles pre y protohistóricos del conjunto. 


$$
[
$$


diámetro, trabados en su construcción con los lienzos rectos, presenta aparejo de sillarejo irregular y mortero de cal. Los mismos cubos presentaban un vierteaguas de mortero para evitar las filtraciones en la base de la estructura. Los tramos rectos, entre cubos, son bastante regulares, entre 24 y $27 \mathrm{~m}$. La zona norte presenta alguna complejidad en el trazado y un baluarte de $16 \mathrm{~m}$. en la parte más avanzada del conjunto, que hoy sustenta el vértice geodésico de $491 \mathrm{~m}$., lo cual ha contribuido a su indefinición morfológica.

La parte sur, destruida por una gravera ya en el primer cuarto de nuestro siglo, presenta hoy un profundo escarpe sobre el Ebro. No podemos asegurar si la fortaleza se cerraría con fábrica o si los mismos escarpes naturales le servirían de protección. Hoy ni un sólo resto permite aventurar una u otra idea.

\section{Disposición general del sistema defensivo en la zona este del recinto (Fig. 2)}

El tramo amurallado de la zona E. de la fortificación, objeto principal de los trabajos arqueológicos realizados en la campaña de 1990, presenta un trazado rectilineo reforzado por torreones semicirculares de $4 \mathrm{~m}$. de radio, dispuestos a distancias más o menos regulares ( $26 \mathrm{~m}$. de separación aprox.).

Para su construcción no se llevaron a cabo labores de cimentación por lo cual las primeras hileras de sillares fueron adaptadas a los desniveles del terreno. Tal disposición permitió conservar estructuras y niveles precedentes de época protohistórica al no apreciarse indicio alguno de foso defensivo excavado en este tramo amurallado; su existencia hubiera supuesto la destrucción de los niveles y estructuras mencionados.

En conjunto, el aparejo presenta en su cara externa una serie de características comunes. Se trata de un sillarejo aplanado, calzado con cantos y abundante argamasa, dispuesto en hileras irregulares. Ocasionalmente incluye sillares mejor trabajados y de mayor tamaño generalmente en las hileras inferiores y en los torreones.

La sección de los lienzos presenta una estructura tripartita (de un espesor medio de 2 metros) con relleno central de cascotes, canto rodado y abundantísima argamasa; la cara interna es similar a la exterior.

Al no disponer de una cimentación lo suficientmente sólida se preservan las primeras hileras de la construcción con unas vierteaguas de argamasa que impide la erosión por parte de los agentes climatológicos, fundamentalmente filtraciones de agua. Tal protección afecta tanto a los paños del lienzo como a los torreones.

\section{Descripción de los elementos}

Torreón 1. De 6,5 m. de anchura máxima, $4 \mathrm{~m}$. de radio, conservándose 1,04 m. de altura media.

Situado en el punto más meridional del trazado, la destrucción de extensas zonas del lado S. del cerro impide determinar el cierre original de la fortaleza en ese punto. Su sillarejo aparece perfectamente imbricado en el de el lienzo A, el más próximo. Su parte central, reventada, no conserva ninguna hilera en su disposición original. 
EL RECINTO MEDIEVAL DEL MONTE CANTABRIA

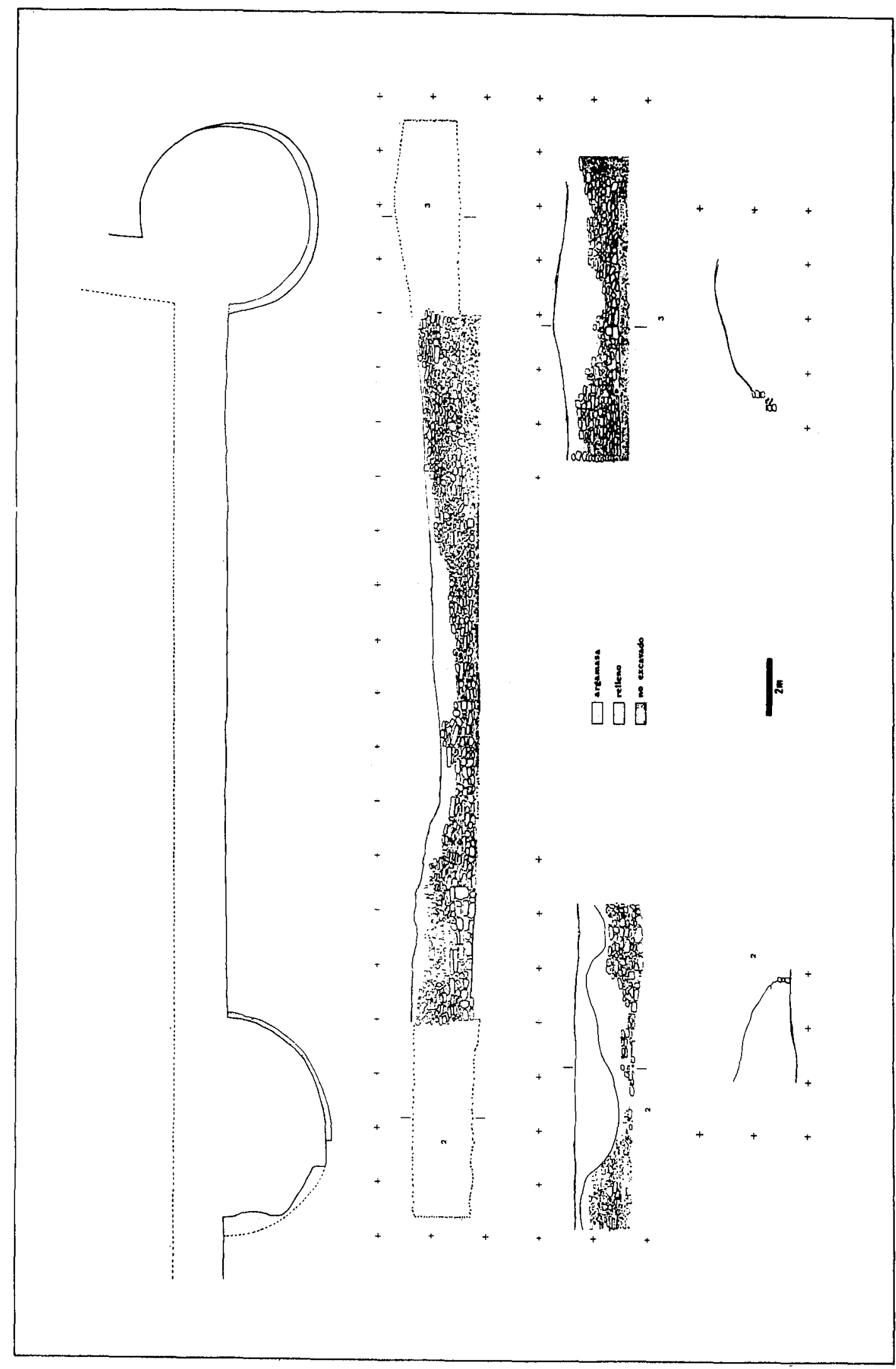

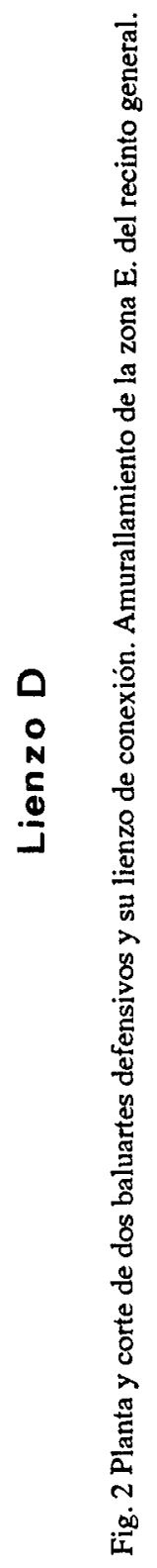


Lienzo $A$. De $25,9 \mathrm{~m}$. de longitud y 2,8 $\mathrm{m}$. de altura máxima.

Presenta un pésimo estado de conservación estando, incluso, destruídos $4 \mathrm{~m}$. de su trazado (como veremos, las estructuras situadas más al norte se hallan menos deterioradas). En la zona próxima al torreón 2 aparecieron los restos de dos muros de sillares fruto de una posible reocupación del lugar en época moderna, ya que ambos se encuentran $30 \mathrm{~cm}$. por encima del vierteaguas.

Torreón 2. De 7,40 m. de anchura máxima, 4,10 m. de radio y $1,75 \mathrm{~m}$. de altura, en la zona mejor conservada.

En contraposición al anterior, su cara externa está adosada a la muralla teniendo el aparejo de ambos modulaciones diferentes, el de torreón es de mayor tamaño y de tendencia cúbica, no aplanada como el de la muralla. Al conservar entre 6 y 7 hileras de sillares vemos como se situan en las superiores algunos elementos más perfeccionados, posiblemente reaprovechados.

Lienzo $B$. De $28,80 \mathrm{~m}$. de largo y $2 \mathrm{~m}$. de altura.

Presenta una disposición similar al lienzo anterior. A $24,3 \mathrm{~m}$. del torreón 2 se encuentran los restos de un suelo de arcilla roja muy compacto, con una base de pequeños cantos rodados. $\mathrm{Al}$ estar $30 \mathrm{~cm}$. por encima del vierteaguas de la muralla deducimos una cronología posterior a la misma; la ausencia de materiales nos impide precisar a que tipo de estructura correspondía.

Torreón 3. De 6,70 m. de anchura máxima, 4,10 m. de radio y $2,30 \mathrm{~m}$. de altura, en su zona mejor conservada.

Con las mismas características que el número 1 , no parece estar adosado al lienzo sino imbricado con él al compartir sillares con éste. Al igual que los anteriores se halla reventado en su parte central.

Lienzo C. De 25,3 m. de largo y $1,7 \mathrm{~m}$. de altura máxima conservada.

Conserva un máximo de 8 hileras, estando las superiores muy desplazadas con respecto a la linea perpendicular de la pared, malformación debida bien a la presión del terreno o a una reconstrucción posterior, hipótesis ésta avalada por la existencia de sillares de mayor tamaño (hasta $1 \mathrm{~m}$. de longitud) entre el sillarejo de las últimas hileras que, además, no presenta restos de argamasa.

En su convergencia con el torreón 3 aparece una estructura ortogonal situada por debajo de la muralla y el vierteaguas, compuesta de pequeña piedras muy irregulares trabadas con argamasa y arcilla.

Torreón 4. De 7,30 m. de anchura máxima, $4,05 \mathrm{~m}$. de radio y $2,40 \mathrm{~m}$. de altura conservada.

Claramente adosado al muro en su capa exterior se rellena el hueco entre ambos con abundante argamasa.

Lienzo $D$. De $25,9 \mathrm{~m}$. de longitud y $2,28 \mathrm{~m}$. de alto.

Se halla formado por sillarejo muy regularizado y ordenado, más cuidado que en el resto de los lienzos. Sólo las hileras superiores presentan una mayor irregularidad y precipitación en su construcción. No pudo ser totalmente excavado en profundidad hasta el vierteaguas, durante esta campaña. 
Torreón 5. De 7,10 m. de anchura máxima en su capa exterior, 6,10 m. en la interna, $4,10 \mathrm{~m}$. de radio y altura máxima de $2,24 \mathrm{~m}$.

Situado en el ángulo entre el paño E. y el N. de la fortificación tiene una planta ultrasemicircular, mejor conservado que los anteriores podemos apreciar dos momentos constructivos que explican las características de los anteriores. A un primer momento corresponde la capa interna del mismo, formado por sillarejo irregular, pequeño y aplanado, trabado con el lienzo correspondiente y roto en su parte central, característica ésta común al resto de los torreones. La capa externa, adosada al lienzo, está formada por sillarejo de mayor tamaño, trabado con abundante argamasa; al tratarse de una obra de remodelación posterior a la construcción de los lienzos, se ha1la adosada a éstos.

\section{C) Tumbas adosadas a la CARA EXTERNA DE LA MURALla}

A lo largo del lienzo A, en la zona más próxima al torreón 1 aparecieron dos tumbas (excavadas en la grava del terreno) dispuestas en sentido longitudinal y paralelas a la dirección de aquella. La primera de ellas quedaba delimitada por losas de arenisca y contenía los restos de dos individuos; uno de ellos, tendido a lo largo de la tumba, se hallaba orientado hacia el sur mientras los restos del otro aparecieron apelotonados a los pies del primero, únicamente el cráneo se situaba también en la cabecera de la tumba. Les acompañaba un mínimo ajuar, apenas un pequeño anillo de cobre sin decoración. La segunda tumba carecía de losas y presentaba unos escasos huesecillos, presentándose levemente excavada en la terraza del rio (Fig. 3).

La misma disposición paralela a la muralla presentaron dos sepulturas aparecidas en el tramo S.O. del recinto durante las campañas de 1981 y 1982. La primera de ellas delimitada lateralmente por cantos y pequeñas losas contenía los restos de un individuo orientado hacia el N.O. La segunda, excavada simplemente en la grava ofreció los de dos individuos de corta edad, contrapuestos y unidos por los pies. Asimismo, durante la campaña de 1981 se recuperaon los restos de otra inhumación en el ángulo formado por el lienzo A con el torreón 2. No se apreció en su momento estructura funeraria alguna aunque la distribución de los huesos permite suponer su adosamiento al ángulo del torreón, es decir, perpendicularmente a la muralla.

Señalaremos, además, la aparición de numerosos huesos humanos durante las labores de limpieza del tramo E. del recinto, desgraciadamente sin contextualización estratigráfica, ni estructuras tumbales detectables.

La ausencia de materiales en las tumbas nos impide dar mayores precisiones sobre las mismas, aunque sí podemos confirmar la utilización del terreno extramuros como necrópolis, en etapa posterior a la edificación el conjunto murado, ya que el mismosirve de pauta a las inhumaciones y algunas de las tumbas cortaron con su estructura la fábrica constructiva de la muralla (especialmente el vierteaguas). 


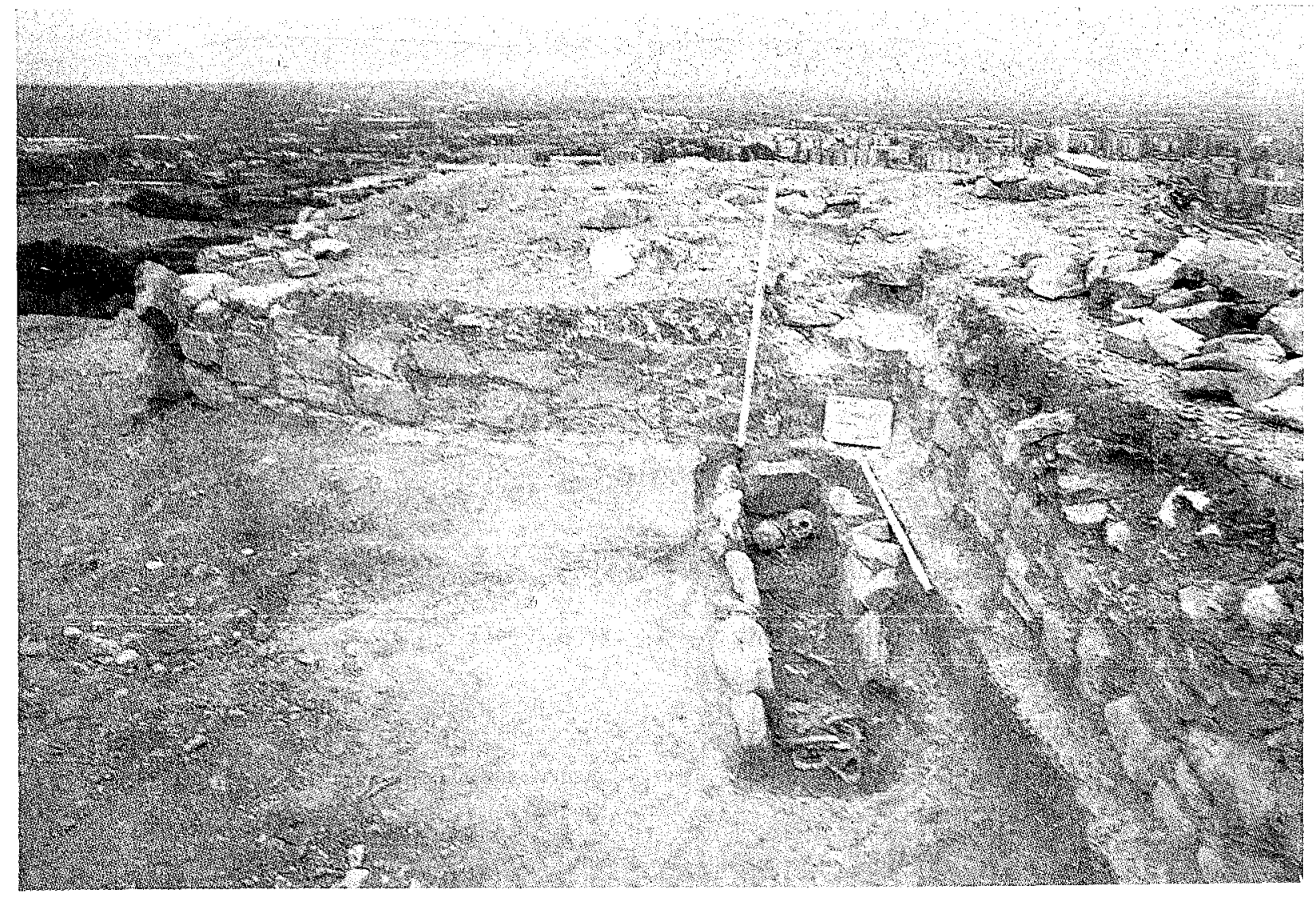

Fig. 3 Tumba con dos inhumados adosada al lienzo A (Este) junto al baluarte 1.

\section{D) CONCLUSIONES ESTRATIGRÁFICAS}

Refiriéndonos estrictamente al tramo E. del recinto amurallado podemos anticipar la siguiente estratigrafía:

Nivel I, protohistórico (Fig. 4). Nos referimos a la gruesa capa de cenizas y a las endebles estructuras de pequeños bloques y argamasa que penetran por debajo de la muralla medieval, a lo largo del lienzo C. Los materiales en ellos aparecidos nos remiten al mundo celtibérico. Poco podemos decir de la ocupación celtibérica del cerro, en esta zona este, aunque sí parece claro que su extensión superaba la del recinto amurallado de época medieval, tal y como aparece en las casas de la zona $\mathrm{W}$, localizadas en campañas anteriores.

Nivel II, medieval (Fig. 5). Su máximo exponente es la muralla a la que nos estamos refieriendo y de la cual ya hemos mostrado sus elementos y características tipológicas. Nos atrevemos a pensar que la zona destinada al hábitat no iba más allá de las fortificaciones al hallarse adosadas al exterior de las mismas las tumbas anteriormente descritas.

Dicho nivel, en esta zona E. del recinto, puede desdoblarse en dos momentos:

Levantamiento general de los lienzos y los torreones. Estos últimos (dispuestos a distancias regulares de $26 \mathrm{~m}$.) se hallarían ensamblados al conjunto compartiendo 


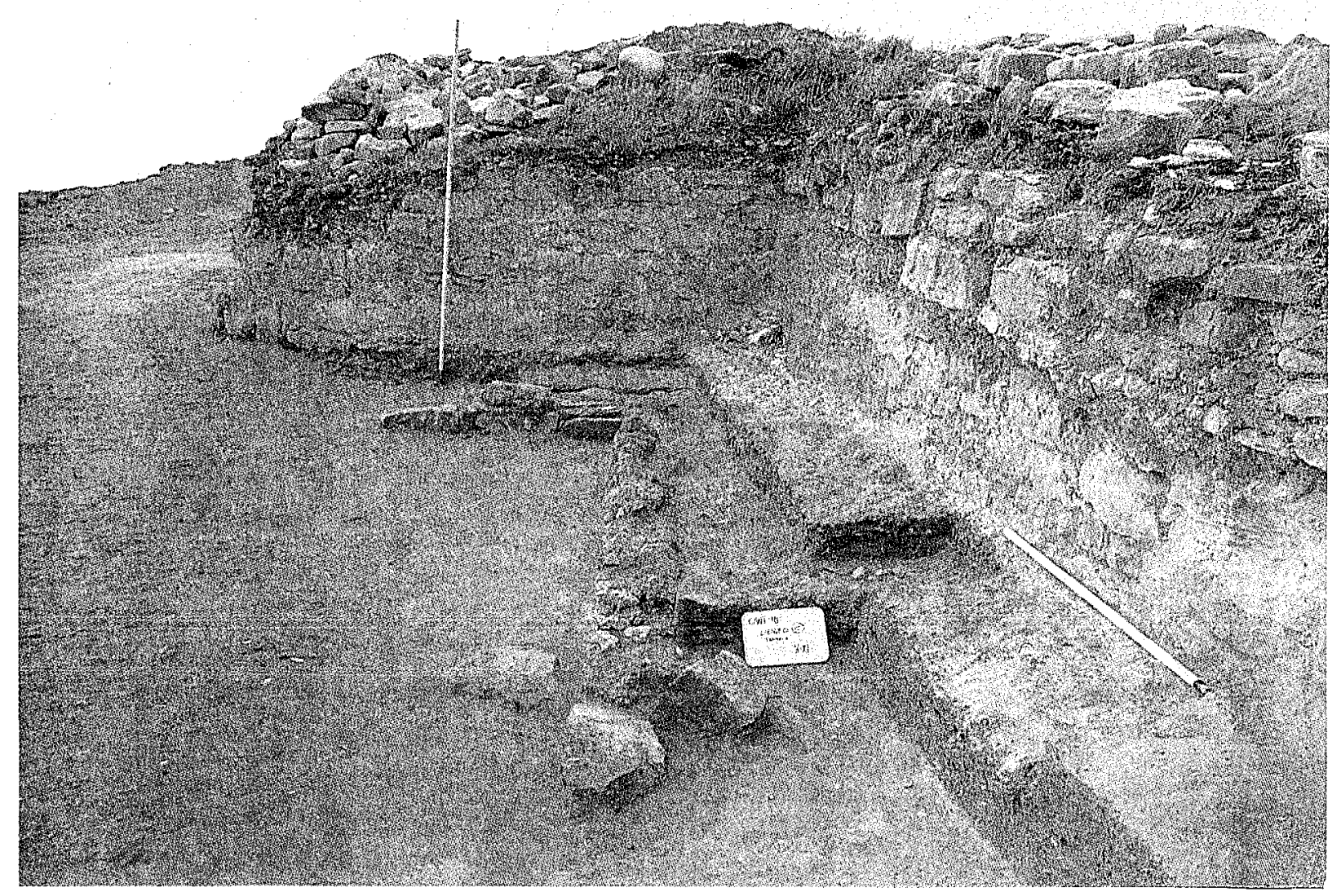

Fig. $4 \mathrm{El} \mathrm{lienzo} \mathrm{C}$ y las estructuras de habitación subyacentes (celtibéricas).

elementos de aparejo. La falta de una talla minuciosa y una modulación especifica del sillarejo y la utilización masiva de argamasa en las junturas sugieren una construcción precipitada, quizá causante del desmoronamiento de la zona central de la mayor parte de los torreones.

El segundo momento de actuación correspondería a la reparación de los desperfectos citados. Para ello es utilizado un sillar más trabajado y de mayor tamaño; tal obra supone el agrandamiento de los torreones de forma que una nueva hilera de sillares es colocada en la semicircunferencia exterior de aquellos. Esta nueva hilera aparecería, por tanto, adosada a los lienzos respectivos, acortándose la longitud de éstos. Esta refacción explicaría la diferencia de tamañó existente entre los torreones, de forma que los más grandes son los que mantienen los restos de tal reparación, los pequeños no la necesitaron o han perdido tal evidencia.

No podemos precisar si la posible reparación del lienzo $\mathrm{C}$ es contemporánea a dichos trabajos. De la misma forma, la ausencia de ajuar funerario significativo en las tumbas nos impide adscribirlas con seguridad a un momento concreto, si bien en todo caso se trata de tumbas posteriores a la elevación de la muralla (fines del XIII).

Por último indicar los restos de adobe, suelos y estructuras aparecidos junto a la muralla de forma dispersa. Presumiblemente se trata de construcciones adosadas en época moderna y comtemporánea propias de la actividad agropecuaria desarrollada en la zona. 


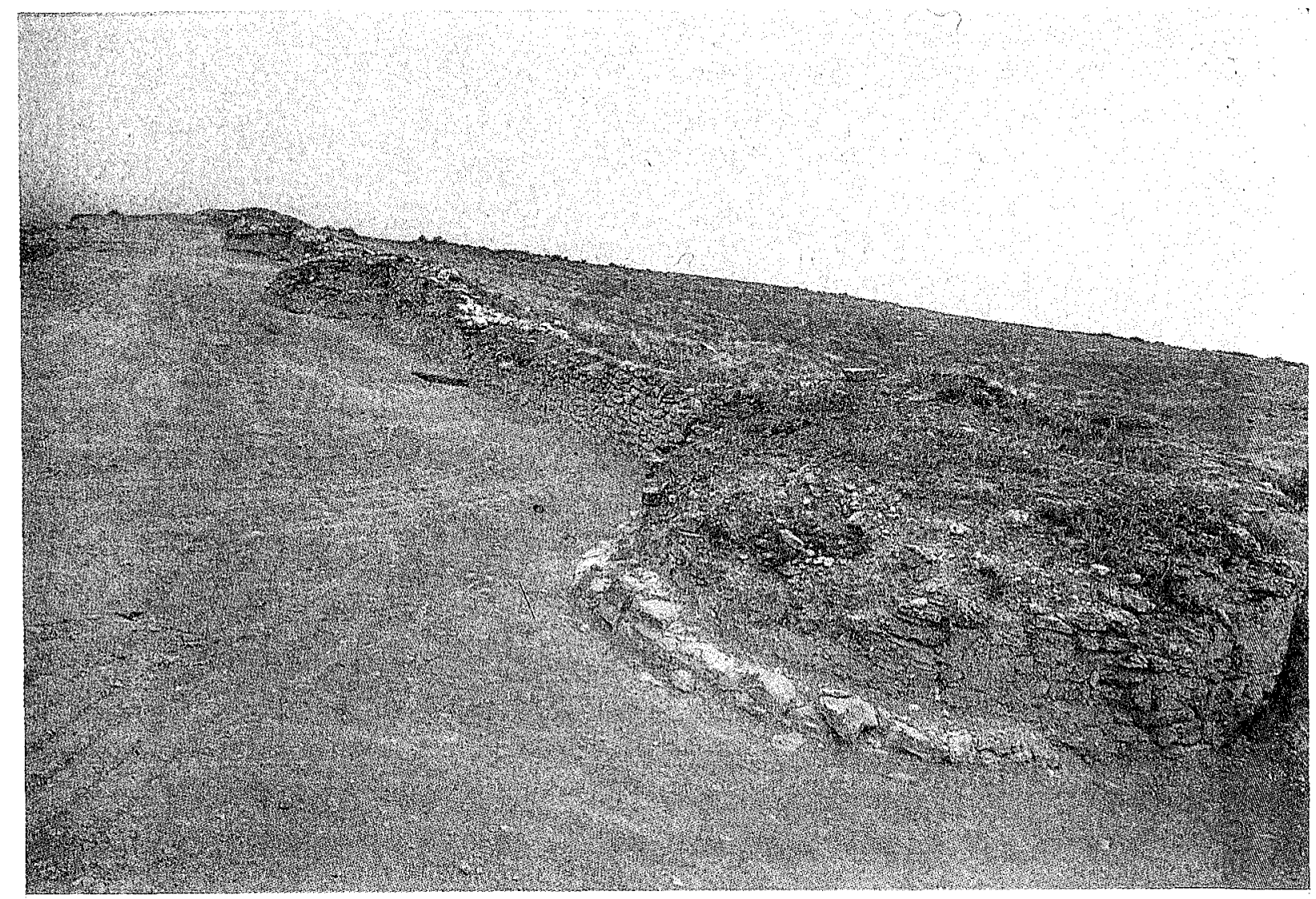

Fig. 5 Lienzos y cubos de la zona E. del recinto medieval.

Los trabajos arqueológicos hasta aquí descritos se ampliarán, en una campaña intensiva, que desarrollaremos durante 1991. La confirmación o modificación del estado actual de la cuestión y la publicación extensa de los datos concretos obtenidos será objeto de una memoria final, a partir de esa última campaña. 